Original paper

\title{
Hereditary spastic paraplegia due to $S P A S T$ mutations in 151 Dutch patients: new clinical aspects and 27 novel mutations
}

de Bot $\mathrm{ST}^{1}$, van den Elzen RTM ${ }^{1}$, Schelhaas $\mathrm{HJ}^{1}$, Willemsen MAAP ${ }^{2}$, Knoers NVAM$^{3}$, Mensenkamp $\mathrm{AR}^{3}$, Kremer $\mathrm{HPH}^{4}$, van de Warrenburg BPC ${ }^{1}$, Scheffer $\mathrm{H}^{3}$

Radboud University Nijmegen Medical Centre, Donders Centre for Brain Cognition and Behaviour, Departments of ${ }^{1}$ Neurology, ${ }^{2}$ Pediatric Neurology, ${ }^{3}$ Human Genetics, Nijmegen, ${ }^{4}$ University Medical Centre Groningen, Dept. Of Neurology, Groningen, the Netherlands.

Scheffer and Van de Warrenburg should be regarded as shared senior authors

Corresponding author's contact information:

ST de Bot, MD

Radboud University Nijmegen Medical Centre, Dept. of Neurology,

PO box 9101, 6500 HB, Nijmegen.

tel: +31(0)2436188 60, fax: +31(0)243541122

E-mail: ST.Bot@neuro.umcn.nl

Word count (excluding title page, abstract, references, figures and tables): 3487

Abstract word count: 220

Key words: SPAST, novel mutations, tremor, exon 4, S44L 


\begin{abstract}
BACKGROUND: In the clinically and genetically heterogeneous group of the hereditary spastic paraplegias (HSPs), mutations in the SPAST gene are most frequently found and cause a pure autosomal dominant form.
\end{abstract}

OBJECTIVE: To provide the clinical and genetic characteristics of Dutch patients with HSP due to a SPAST mutation (SPG4).

METHODS: SPAST mutation carriers were identified through a comprehensive national database search. Available medical records were reviewed.

RESULTS: 151 mutation carriers carried 60 different changes in the SPAST gene, of which one was a known polymorphism and 27 were novel. Missense mutations were most frequently found (39\%). Clinical information was available from 72 mutation carriers. Age at onset ranged from 1 to 63 years with a bimodal peak distribution in the first decade and above age 30. The predominantly pure spastic paraplegia was accompanied by deep sensory disturbances and sphincter problems in almost 50\%. An additional hand tremor was found in 10\%. Patients with missense mutations and exon deletions did not reveal a distinctive phenotype.

CONCLUSIONS: Dutch SPAST mutation carriers show a broad mutation spectrum, with 27 novel mutations in the present series. A bimodal peak distribution in age at onset was found and an accompanying tremor as peculiar feature of SPG4. The pathogenicity of S44L, the first exon 4 mutation, and a possible autosomal recessive mode of inheritance are discussed.

Key words: $S P A S T$, novel mutations, tremor, exon 4, S44L 


\section{Introduction}

The hereditary spastic paraplegias (HSPs) constitute a genetically and clinically heterogeneous group of disorders of which the main clinical feature is progressive lower limb spasticity due to pyramidal tract dysfunction. The cardinal signs result from a "dying back" degeneration of the corticospinal tracts and dorsal column, predominantly affecting axonal transport of the longest fibers that innervate the lower extremities.[1] Neuro-imaging of HSP patients can reveal spinal cord atrophy, mostly at the thoracic level.[2] In addition, corpus callosum atrophy (although more common in autosomal recessive HSP), atrophy of the cerebellum, and white matter lesions have all been found in HSP.[3,4]

If neurological signs are limited to the lower limbs, eventually accompanied by urinary urgency and mildly impaired vibration sense at the ankles, HSP is classified as "pure".[5] In contrast, HSP is classified as a "complicated" form if additional neurological signs are present, such as mental retardation, extrapyramidal signs, visual dysfunction, epilepsy, or systemic involvement.[5]

HSP may be inherited as an autosomal dominant (AD), an autosomal recessive (AR) or an Xlinked disease, with more than 40 loci identified.[6] AD transmission is observed in 70 to $80 \%$ of all HSP cases in Western countries.[7] Mutations in SPAST are responsible for about $40 \%$ of the AD-HSP cases and cause a predominantly pure HSP.[4] Over 150 mutations of different types (missense, nonsense and splice mutations, deletions, and insertions) along the SPAST gene have been reported. SPAST is a gene encoding the spastin protein, which is a member of the ATP-ases Associated with various cellular Activities (AAA) family.[4] Both the AAA-domain and the MIT(microtubule interacting and trafficking)-domain of the SPAST gene play an important role. Recent studies confirmed that spastin possesses microtubulesevering activity, necessary for axonal transport.[8] A loss of function of spastin due to a SPAST mutation, could thus lead to axonal dysfunction. 
There is a broad clinical spectrum of SPAST mutations, even within families, and the genotype-phenotype correlations remain largely unclear. To further expand our knowledge on the phenotypic and genetic spectrum of SPAST-linked HSP, we studied the mutations and disease characteristics of a comprehensive cohort of Dutch SPAST mutation carriers and found some new features.

\section{Methods}

\section{$\underline{\text { Patients }}$}

The DNA diagnostic laboratory within the Dept. of Human Genetics of the Radboud University Nijmegen Medical Centre (RUNMC) is the single national laboratory to provide SPAST mutation analysis for the Netherlands, being offered since 2000 . Thus, we were able to identify all Dutch SPAST mutation carriers from a laboratory information system query. Available medical records and imaging data were reviewed. A clinicogenetic HSP-database was composed containing clinical information from history, with the age of onset as mentioned by the patient, and neurological examination, combined with the results of genetic testing and additional investigations (CT-MRI-EMG-laboratory-other). The study has been carried out in the Netherlands in accordance with the applicable rules concerning the review of studies by research ethics committees and informed consent.

\section{Genetic analysis:}

Mutation analysis of the SPAST gene was performed by sequencing of the coding sequences including flanking intronic sequences as well as multiplex ligation-dependent probe amplification (MLPA) assay in all patients, using the methods described previously.[9,10] NM_014946.3 was used as reference sequence, with nucleotide 1 corresponding to the A of 
the start codon. If the results were indicated by multiple flanking probes within the MLPA test, they were considered as indicative for a true deletion. Test results were confirmed by an independent test according to standard procedures. Determination of pathogenicity of point mutations was obtained by an in silico approach using the prediction programs SIFT (Sorting Intolerance from Tolerance; http://sift.jcvi.org), Align GVGD (http://agvgd.iarc.fr/) and POLYPHEN (Polymorphism Phenotyping; http://genetics.bwh.harvard.edu/pph/).[11,12]

\section{Results}

From July 2000 till July 2008, mutation analysis was performed in 1386 Dutch patients with suspected HSP, in the presence or absence of affected family members. This yielded 151 (i.e. $11 \%$ ) positive carriers originating from 84 families. Five patients were sporadic. We had sufficient clinical data from 72 carriers (from 47 families) to study the phenotypic spectrum.

\section{Genotypic spectrum}

The 151 mutation carriers originating from 84 families were found to carry 60 different changes in the SPAST gene, one of which is a known polymorphism (p.Ser44Leu; see below and the discussion). Overall, we found 23 missense mutations (39\%), 10 splice site mutations (17\%), 9 small deletions (15\%), 8 deletions of single or multiple exons (14\%), 6 nonsense mutations (10\%), 2 duplications (3\%), and 1 insertion (2\%) (Supl. table 1). Mutations occurred throughout the whole gene. According to the international electronic database (www.hgvs.org), we identified 27 novel SPAST mutations (Table 1). By MLPA analysis we identified 8 different large exonic deletions in the SPAST gene, 3 of which are novel. Most families showed private mutations. Some mutations were observed more frequently, like c.1174del (p.Ala392fs). All, but one, novel missense mutations are clustered in the AAA- 
domain. The other mutation is located in the MIT (microtubule interacting and trafficking) domain (Figure 1).

\section{Phenotypic spectrum}

The phenotype could be defined for 72 cases. Five of them were asymptomatic SPAST mutation carriers (according to their history) and were not included in determining the phenotypic spectrum, apart from the tendon reflexes (table 2). In total, 47 distinct families could be identified based on available family information.

The family history of these patients revealed an autosomal dominant mode of inheritance with certainty in $72 \%$ of the 72 cases. Five cases were sporadic (6.9\%). In one family an autosomal recessive mode of inheritance was observed, associated with a unique missense mutation in exon 14 (c.1600C>G: p.Leu534Val). The two affected siblings, who showed a pure spastic paraparesis, were homozygous for the mutation, while the heterozygous consanguineous parents were fully asymptomatic at ages of 73 and 68 years (see also the Discussion).

The age of onset varied from 1 to 63 years (mean $33.4 \pm$ SD 18.3 years), and showed a bimodal distribution with a first peak in the first decade and a second peak between 30 and 60 years (figure 2).

Most patients presented with gait difficulty (Table 2). The overall phenotype was that of a slowly progressive, mostly pure spastic paraparesis with only little or no arm involvement. Strength and tone of the upper limbs were almost always normal, but the tendon reflexes in the arms were brisk in $61 \%$. Mild cerebellar ataxia of the arms was present in a few cases. Ataxia of gait was more common; $32 \%$ of the patients presented with a spastic ataxic gait and/or difficulty with tandem gait. Muscle tone of the lower limbs was increased in most patients $(85 \%)$. Muscle strength was only mildly impaired or normal, with $80 \%$ of cases who 
demonstrated strength of at least MRC 4. The small group with a (lower limb) muscle strength of less than MRC 4 showed a significant longer disease duration (mean of 24 years) compared to the group with a strength of at least MRC 4 (mean duration of 10 years). Brisk reflexes of the lower limbs were found in $95 \%$ with Babinski signs in $86 \%$ (in $72 \%$ bilaterally). About one third of the patients used some sort of walking aid, $15 \%$ was completely wheelchair bound.

Deep sensory modalities were disturbed in almost half of the patients (47\%). Vibration sense was predominantly impaired. Bladder disturbances, predominantly urinary urgency, were present in $42 \%$ of the patients, and anal sphincter disturbances in $15 \%$.

Swallowing problems were mentioned by 2 patients (3\%), in whom mild dysarthria was also noticed.

Patients with missense mutations did not show a significant earlier age of onset (33.8 years vs. 33.3), compared to other types of mutations. In both the <35 age group and in the $>35$ age group we observed an approximately $40 \%$ proportion of missense mutations, respectively $38 \%$ and $43 \%$, without a preference for the younger age of onset group. The clinical presentation and the age of onset of the patients with an exonic deletion was similar to those with loss of function mutations, i.e. missense, nonsense and splice site mutations.

Neuro-imaging of the brain and the spinal cord was performed in 39 patients. Eight $(21 \%)$ of these scans showed HSP-associated abnormalities: 4 patients had atrophy of the spinal cord; the others had atrophy of the cerebrum $(n=1)$, cerebellum $(n=1)$ and a thin corpus callosum $(n=2)$. Unspecific white matter lesions (WML) were seen in $4(10 \%)$ patients, who were at that time aged 44 to 62 years.

\section{Complex phenotype}


Over one fifth $(22 \%)$ of the patients presented with a relatively mild complex phenotype (table 3), based on clinical and/or imaging features. The abnormalities were mostly minor. A mild tremor of the arms was present in $7 / 67$ patients (10\%). Three patients showed a postural tremor, three patients an intention tremor and one patient an action tremor. A more severe complex phenotype, based for example on the presence of mental retardation or dementia, was rare.

\section{Clinical data of the S44L family}

We found one family in which the known p.Ser44Leu polymorphism is segregating. No additional pathogenic SPAST mutation was identified. The mother was heterozygous for this variant and showed no signs or symptoms. The father was also heterozygous, but presented with sphincter problems at the age of five years. On examination, his legs were hypertonic with increased tendon reflexes and Babinski's sign bilaterally. The son, who was homozygous for the p.Ser44Leu variant, presented with sphincter disturbances at age six, but without any difficulty of gait or abnormalities on examination (see also the discussion).

\section{Discussion}

SPAST mutations comprise by far the most frequent form of autosomal dominant spastic paraplegia (between 15 and $40 \%$ of AD-HSP's).[4,13] Our cases represented $11 \%$ of all requests for SPAST mutation analysis, but it should be kept in mind that these requests emerged from an unselected cohort that included sporadic and even probably recessive paraplegia cases. A German study revealed 17\% SPAST mutations in a comparable population suffering from spastic paraplegia with or without a family history.[9] 
Here, we report a comprehensive overview of the phenotypic and genotypic spectrum of all identified SPAST mutation carriers in the Netherlands. Since the RUNMC is the only centre in the Netherlands providing SPAST mutation analysis, this overview includes all known SPAST carriers in the Netherlands. The identification of 151 SPAST mutation carriers results in a prevalence of 0.92 carriers per 100.000 in the Netherlands.

\section{Mutations}

Of the 60 different changes in the SPAST gene identified, one was a previously described nonpathogenic polymorphism (p.Ser44Leu), 59 were true mutations. We also confirmed the existence of exonic deletions, which is consistent with findings recently reported.[13,14] In our cohort, missense mutations were the most frequent (39\%), followed by splice site mutations (17\%) and small deletions (15\%). Comparable figures were found in two other studies.[15,16]

The most frequent mutation was a previously described mutation (c.1174del), in the AAA

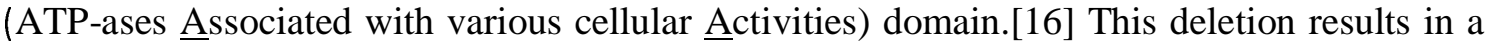
frameshift after the alanine at position 392 and was found in 5 out of 84 families (6\%).

A novel finding is the deletion of exon 4 in one family suffering from a well-defined spastic paraplegia. The pathogenicity of this mutation is not certain, as SPAST is alternatively spliced. Exon 4 is spliced out in one transcript, coding for a slightly shortened isoform (NM_199436.1). The transcript without exon 4 is still in frame, and it is not known what the functional consequences are of this deletion.

\section{Mode of inheritance}

In $7 / 84(8 \%)$ families the mode of inheritance was uncertain, but probably best fits with incomplete penetrance of an autosomal dominant trait, or incomplete clinical assessment of 
the parents. Incomplete penetrance and reduced or delayed expression, which is depending on the age at the time of examination, have been described before in a relatively high proportion (24.1\%) of SPAST mutation carriers.[17] In this Irish study even a case of true non-penetrance was observed.

Five cases seemed sporadic $(6.9 \%)$ which is due to a de novo mutation, incomplete penetrance, somatic mosaicism, non-paternity, or incomplete clinical assessment of the parents. De novo mutations have been found in $6 \%$ of cases in an Italian study and in $12 \%$ in a French study.[18,19] As we have not systematically investigated all family members, we cannot further comment on our sporadic cases.

One family presented with a (pseudo-)recessive inheritance. Both parents, who were consanguineous, had a heterozygous missense mutation, c.1600C >G (p.Leu534Val), without signs or symptoms at ages 73 and 68 years, respectively. Their two children, homozygous carriers of the mutation, presented with a pure spastic paraparesis, both with an onset at age 39 years. Both patients were tested negative for SPG7. There are several explanations for these findings. First, this mutation (c.1600C >G, p.Leu534Val) may only be pathogenic in a homozygous state (thus representing a recessive disease). Second, the opposite SPAST allele may in fact be (partly) deleted. The allele carrying the c.1600C $>\mathrm{G}$ mutation would thus appear to be homozygous after sequencing. This, however, is very unlikely as both parents are carrier of the mutation. The third explanation is that the mutation is a non-pathogenic polymorphism. In that case, the diagnosis cannot be confirmed genetically. However, a different heterozygous missense mutation affecting the same amino acid residue, c.1601T $>C$ (previous nomenclature in literature: c.1726T >C); p.Leu534Pro, has been described causing an autosomal dominant pure HSP.[20] The leucine to valine change (both nonpolar, hydrophobic amino acids) is less dramatic than the leucine to proline change (a moderately polar, negatively charged amino acid with the additional capacity to form a hydrogen bond). 
This could well explain the fact that L534P acts in a dominant way, whereas L534V only has a pathogenic effect when present in a homozygous state. The p.Leu534Val concerns a conservative change of a strongly conserved amino acid. Due to the high conservation, the change is predicted to affect protein function by online prediction tools SIFT and Align GVGD (refs 1, 2). Also the fact that p.Leu534Val is located in the AAA domain, may cause it to be pathogenic.[11,12]

\section{$S 44 L$}

S44L (p.Ser44Leu) is a relatively rare, but well-described non-pathogenic polymorphism. In a North American control population, the L44 allele was found in $0.6 \%$ of individuals examined and in a British control population even in 3.1\%.[15,21] However, a role as a phenotypic modifier is also attributed to $\mathrm{S} 44 \mathrm{~L}$ previously.[15,21]

One family in which this polymorphism is segregating was found in our study. The father's disease, which is compatible with an early onset spastic paraplegia, may be caused by an as of yet unidentified mutation in one of the genes underlying paraplegia, suggesting a role for p.Ser44Leu as a genetic modifier. This may include an unidentified mutation in a regulatory or intronic region of SPAST. An English severely affected child with compound heterozygosity for p.Pro361Leu and p.Ser44Leu in the SPAST gene supports this hypothesis.[22] Urinary urgency and frequency together with hyperreflexia were the main features in this family, comparable to our case. In case of co-occurrence of another SPAST mutation, S44L would act via a gain of function mechanism and worsen a primary 'loss of function' effect caused by a different loss of function mutation occurring in trans.[23] An imbalance between short and long isoforms could be responsible for a mild pathogen effect of an isolated S44L mutation.[23] Another explanation could be that p.Ser44Leu shows a high variability in phenotypic expression, rather than being a genetic modifier. Two Norwegian 
families with HSP and a p.Ser44Leu polymorphism were described; both without an identified pathological SPAST mutation.[24] Some of the family members were homozygous, others heterozygous for the polymorphism, associated with or without clinical symptoms. Development of a more severe disease due to a homozygous mutation of S44L, as in the son in our case, has been suggested before.[16]

Thus, rather than being completely non-pathogenic and innocent, it should be suspected that p.Ser44Leu, under specific conditions, may cause a mild HSP phenotype, with a more severe phenotype, when combined with a classical SPAST mutation, or in a homozygous mutation.

\section{Phenotype}

The phenotype of gait difficulty due to a slowly progressive pure spastic paraparesis with little or no arm involvement, accompanied by impairment of deep sensory modalities and sphincter problems, is fully consistent with the phenotype as reported in the literature.[15,16] Compared to almost $42 \%$ bladder disturbances and $14.5 \%$ anal sphincter disturbances in our cohort, urinary urgency was only found in $21 \%$ of the British cases.[15] This difference may be caused by the intensity of questioning rather than by a true difference. Also the proportion of patients who were wheelchair bound in our study (15\%), is comparable with the $17 \%$ reported previously.[4] In contrast, swallowing problems and dysarthria, which were present in 2 of our 67 symptomatic patients (3\%), have not been reported previously.

One-fifth of our patients had a, mostly mild, complex phenotype, with additional signs or symptoms not attributable to the pyramidal tract or dorsal columns. Hand tremor was observed in $10 \%$ of SPAST patients. A literature search did not reveal any recent reports of tremor in SPAST patients, but might have been overlooked clinically. In a family description from 1963 a 'slight intention tremor' in four patients was mentioned as an atypical feature of AD-HSP.[25] The other additional neurological symptoms or signs found in a part of our 
cohort, such as neuropathy, epilepsy, mental retardation, cerebellar atrophy and thinning of the corpus callosum have previously been described in SPAST patients.[6] A mild form of dementia, which has been described as an associated symptom in SPAST patients, was however only found in one of our SPAST patients.[26] Based on neuropsychological testing, CSF findings and brain MRI in our patient, this cortical dementia could be either SPASTrelated or Alzheimer's dementia.

The mean age of onset in our cohort was $33.4 \pm 18.3$ years, ranging from 1 to 63 years, with a bimodal distribution showing a peak in the first decade and a second peak in the $4^{\text {th }}$ till $6^{\text {th }}$ decade. A mean age of onset of 29-34 years with a comparable broad range was found in previous studies.[15,16,17] However, a clear bimodal distribution, as we describe, was not found in these European studies and we clearly found more patients with an age of onset in the $1^{\text {st }}$ and $6^{\text {th }}$ decade (both $19 \%$ ), compared to other reports. The challenge here is to assess the exact age of onset. Currently, this is estimated by careful history taking, but this method may yield systematic error as many patients probably go through an initial phase in which they do not yet experience symptoms, while hyperreflexia could already be present.

In the group with exonic deletions a similar phenotype was found in our study, as in the group with loss of function mutations caused by a base pair substitution or a small deletion or insertion, as previously has been described.[13,14] In contrast to other studies, our results do not confirm the recently proposed hypothesis of an earlier onset of the disease when caused by a missense mutation in the AAA domain.[10]

Spinal cord atrophy, as was found in 4 of our patients, has been described in SPAST patients.[2] In the same study, MRI of the brain was normal and the thickness of the corpus 
callosum did not differ from healthy controls.[2] Another study also showed atrophy of the midthoracic cord, and in this study the corpus callosum was indeed significantly smaller in patients in comparison to healthy controls.[3] However, in that study not all patients were tested for SPAST mutations, but were merely diagnosed with pure HSP. On the contrary, another study states that a thin corpus callosum is not associated with SPAST-linked HSP.[27] We found 2 patients with a thin corpus callosum, supporting a possible association with SPAST.

Four patients showed so-called unspecific WML on brain-MRI. It is questionable whether this finding is of any value, i.e. linked to HSP. It may be related to age, as the youngest patient with WML was 44 years old. The literature is also ambiguous. In some, mostly older papers, WML are indeed linked to HSP.[28,29] Others suggest that WML are not more common in HSP patients then in controls.[30] No age-matched comparisons have yet been conducted.

\section{Conclusion}

Dutch patients with HSP due to a SPAST mutation show a broad mutation spectrum, with 59 different mutations identified of which 27 are novel. Clinically, a predominantly pure spastic paraparesis was observed, with a wide range of age at onset, consistent with other reports of large populations of SPAST patients in Western countries.

Interestingly, a distinct bimodal peak distribution of age at onset, at the first decade and between 30 and 60 years of age, was found in the Dutch population. Compared to previous studies, an age at onset before 10 and after 50 years was relatively more frequent. Although urinary urgency is frequently described in the literature, bladder and anal sphincter disturbances were more common observed in this study and might have been underestimated. As a complicating feature, a tremor was found in almost $10 \%$ of the patients, a feature which 
needs more detailed investigation in future studies. The same applies to a possible autosomal recessive mode of inheritance of the missense mutation in exon 14 (c.1600C $>\mathrm{G}$ : p.Leu534Val), the role of the p.Ser44 Leu variant and of exon 4 mutations.

\section{Acknowledgements: none}

\section{Competing interests: none}

\section{Funding: none}

Copyright licence statement: The Corresponding Author has the right to grant on behalf of all authors and does grant on behalf of all authors, an exclusive licence (or non exclusive for government employees) on a worldwide basis to the BMJ Publishing Group Ltd and its Licensees to permit this article (if accepted) to be published in the Journal of Neurology, Neurosurgery \& Psychiatry editions and any other BMJPGL products to exploit all subsidiary rights, as set out in our licence (http://jnnp .bmjjournals.com/ifora/licence.pdf)." All authors have seen the manuscript and agree with the contents of the manuscript and all authors guarantee that the manuscript will not be published elsewhere in any language without the consent of the copyright owners. The submission is not under review at any other publication. All authors declare that there are no conflicts of interest.

Figure 1: Schematic figure showing the structural domains of SPAST. Indicated are all missense mutations identified in this study. Open circles indicate known mutations, closed circles indicate novel mutations. All but one novel missense mutation was detected in the AAA domain; the other mutation was detected in the MIT domain.

Figure 2: distribution (in \%) of the age at onset in 67 HSP patients with SPAST mutations, with a peak of $19 \%$ with an age of onset before 10 years and a peak of $25 \%$ with an age of onset between 40 and 49 years. 


\begin{tabular}{|c|c|c|c|c|c|}
\hline No. & Exon/intron & $\begin{array}{l}\text { cDNA (nucleotide } \\
\text { change) }\end{array}$ & $\begin{array}{l}\text { Amino acid } \\
\text { change }\end{array}$ & $\begin{array}{l}\text { Mutation } \\
\text { type }\end{array}$ & Effect \\
\hline 1 & Ex 1 & c. $153 \mathrm{C}>\mathrm{G}$ & p.Tyr51X & Nonsense & $\begin{array}{l}\text { Premature termination } \\
\text { codon (PTC) }\end{array}$ \\
\hline 2 & Ex 1 & c.155_156dup & p.Phe53fs & Duplication & $\begin{array}{l}\text { Frameshift leading to } \\
\text { downstream PTC }\end{array}$ \\
\hline 3 & Ex 1 & c.310del & p.Ala104fs & Deletion & Frameshift leading to PTC \\
\hline 4 & Ex 1 & c.328_340del & p.Gly110fs & Deletion & Frameshift leading to PTC \\
\hline 5 & Ex 2 & c. $484 \mathrm{G}>\mathrm{A}$ & p.Val162lle & Missense & $\begin{array}{l}\text { Conservative change in } \\
\text { residue conserved up to } \\
\text { frog; MIT domain }\end{array}$ \\
\hline 6 & Ex 5 & c.790del & p.His264fs & Deletion & Frameshift leading to PTC \\
\hline 7 & Ex 7 & c. $1061 \mathrm{~T}>\mathrm{A}$ & p.Leu354X & Nonsense & PTC \\
\hline 8 & Ex 7 & c. $1066 \mathrm{G}>\mathrm{A}$ & p.Glu356Lys & Missense & $\begin{array}{l}\text { Non-conservative change } \\
\text { of a strong conserved } \\
\text { amino acid in the AAA- } \\
\text { cassette }\end{array}$ \\
\hline 9 & Ex 7 & c.1069del & p.lle357fs & Deletion & Frameshift leading to PTC \\
\hline 10 & Ex 7 & c. $1093 \mathrm{C}>\mathrm{T}$ & p.Pro365Ser & Missense & $\begin{array}{l}\text { Mutation in the AAA- } \\
\text { cassette that influences the } \\
\text { correct splicing of the gene }\end{array}$ \\
\hline 11 & Ex 8 & c. $1144 G>C$ & p.Gly382Arg & Missense & $\begin{array}{l}\text { Non-conservative change } \\
\text { of a very strong conserved } \\
\text { amino acid in the AAA- } \\
\text { cassette }\end{array}$ \\
\hline 12 & $\ln 8$ & c. $1174-2 A>C$ & p.? & Splice site & $\begin{array}{l}\text { Influences the splice } \\
\text { acceptor of exon 9. A skip } \\
\text { is very likely. }\end{array}$ \\
\hline 13 & Ex 9 & c. $1220 \mathrm{G}>\mathrm{T}$ & p.Ser407lle & Missense & $\begin{array}{l}\text { Non-conservative change } \\
\text { of a conserved residue in } \\
\text { the conserved AAA- } \\
\text { cassette }\end{array}$ \\
\hline 14 & $\ln 9$ & c. $1245+1 G>C$ & p.? & Splice site & $\begin{array}{l}\text { Influences the splice donor } \\
\text { site of exon } 9 \text {. A skip is } \\
\text { very likely. }\end{array}$ \\
\hline 15 & Ex 10 & c. $1266 \mathrm{G}>\mathrm{C}$ & p.Leu422Phe & Missense & $\begin{array}{l}\text { Mutation of a conserved } \\
\text { residue in the conserved } \\
\text { AAA-cassette }\end{array}$ \\
\hline 16 & Ex 11 & c. $1334 \mathrm{G}>\mathrm{A}$ & p.Ser445Asn & Missense & $\begin{array}{l}\text { Mutation of a conserved } \\
\text { residue in the conserved } \\
\text { AAA-cassette }\end{array}$ \\
\hline 17 & Ex 11 & c. $1378 \mathrm{C}>\mathrm{A}$ & p.Arg460Ser & Missense & $\begin{array}{l}\text { Mutation of a conserved } \\
\text { residue in the conserved } \\
\text { AAA-cassette }\end{array}$ \\
\hline 18 & Ex 12 & c. $1444 G>C$ & p.Val482Leu & Missense & $\begin{array}{l}\text { Mutation of a conserved } \\
\text { residue in the conserved } \\
\text { AAA-cassette }\end{array}$ \\
\hline 19 & Ex 13 & c. $1500 \_1501$ ins $T$ & p.lle501fs & Insertion & Frameshift leading to PTC \\
\hline
\end{tabular}




\begin{tabular}{|c|c|c|c|c|c|}
\hline 20 & Ex 13 & c.1534_1536del & p.Glu512del & Deletion & $\begin{array}{l}\text { Influences the function of } \\
\text { the AAA-cassette domain }\end{array}$ \\
\hline 21 & Ex 14 & c. $1600 C>G$ & p.Leu534Val & Missense & $\begin{array}{l}\text { Mutation of a conserved } \\
\text { residue in the conserved } \\
\text { AAA-cassette }\end{array}$ \\
\hline 22 & Ex 15 & c.1628dup & p.Tyr544fs & Duplication & Frameshift leading to PTC \\
\hline 23 & Ex 15 & c. $1685 G>C$ & p.Arg562Pro & Missense & $\begin{array}{l}\text { Mutation of a conserved } \\
\text { residue in the conserved } \\
\text { AAA-cassette }\end{array}$ \\
\hline 24 & Ex 17 & c.1817del & p.Arg606fs & Deletion & Frameshift leading to PTC \\
\hline 25 & Ex $3-17$ & c.503-?_1851+?del & Unknown & $\begin{array}{l}\text { Exon } \\
\text { deletion }\end{array}$ & $\begin{array}{l}\text { Deletion of major part of } \\
\text { the SPAST gene leads to } \\
\text { an unstable transcript }\end{array}$ \\
\hline 26 & Ex 4 & c.587-?_682+?del & Unknown & $\begin{array}{l}\text { Exon } \\
\text { deletion }\end{array}$ & $\begin{array}{l}\text { In frame deletion of } 32 \\
\text { amino acid residues }\end{array}$ \\
\hline 27 & Ex 14-17 & $\begin{array}{l}\text { c. } 1537- \\
? .1851+? \mathrm{del}\end{array}$ & Unknown & $\begin{array}{l}\text { Exon } \\
\text { deletion }\end{array}$ & $\begin{array}{l}\text { Deletion of } 3 \text { ' part of the } \\
\text { SPAST gene will lead to a } \\
\text { short and unstable } \\
\text { transcript }\end{array}$ \\
\hline
\end{tabular}

Table 1: List of 27 novel mutations identified in the SPAST gene in our HSP cohort 


\begin{tabular}{|c|c|c|c|}
\hline Characteristic & & Characteristic & \\
\hline Men : women & $3: 2$ & Atrophy lower $\operatorname{limb}(\%)$ & $5 / 43(12 \%)$ \\
\hline Mean age at onset (years) $(n=67)$ & $\begin{array}{c}33.4 \pm \text { SD } 18.3 \\
\text { (range } 1 \text { to } 67 \text { years) }\end{array}$ & Spastic gait (\%) & $47 / 66(71 \%)$ \\
\hline \multirow{2}{*}{$\begin{array}{l}\text { Mean age at examination (years) } \\
\text { Family history }(\%) \text { Positive }\end{array}$} & $\begin{array}{r}46.2 \pm \text { SD } 16.7 \\
\text { (range } 1 \text { to } 72 \text { years ) }\end{array}$ & \multirow{2}{*}{$\begin{array}{l}\text { Walking aid (stick or wheelchair) (\%) } \\
\text { Wheelchair bound completely }(\%)\end{array}$} & $19 / 59(32 \%)$ \\
\hline & $67 / 72(93 \%)$ & & $9 / 59(15 \%)$ \\
\hline Mental retardation/deterioration $(\%)$ & $2 / 67(3 \%)$ & Reflexes upper limbs & \\
\hline Abnormalities of cranial nerves/brainstem (\%) & $6 / 62(10 \%)$ & Normal & $25 / 66(38 \%)$ \\
\hline \multirow{2}{*}{$\begin{array}{l}\text { Eye movements } \\
\text { Optic atrophy }\end{array}$} & $1 / 62(2 \%)$ & \multirow{2}{*}{$\begin{array}{l}\text { Brisk } \\
\text { Decreased }\end{array}$} & $40 / 66(61 \%)$ \\
\hline & $3 / 49(6 \%)$ & & $1 / 66(2 \%)$ \\
\hline Speech & $4 / 62(7 \%)$ & Reflexes lower limbs & \\
\hline Swallowing & $2 / 61(3 \%)$ & Normal & $3 / 72(4 \%)$ \\
\hline Upper limb weakness (\%) & & Brisk & $68 / 72(95 \%)$ \\
\hline Absent (MRC 5) & $57 / 60(95 \%)$ & Decreased & $1 / 72(1 \%)$ \\
\hline Mild (MRC 4-5) & $3 / 66(5 \%)$ & Babinski sign & $61 / 71(86 \%)$ \\
\hline Lower limb weakness (\%) & & Bilateral & $51 / 71(72 \%)$ \\
\hline Absent (MRC 5) & $29 / 62(47 \%)$ & Unilateral & $10 / 71(14 \%)$ \\
\hline Mild (MRC 4) & $21 / 62(34 \%)$ & Ataxia (\%) & \\
\hline Moderate (MRC 3) & $6 / 62(10 \%)$ & Upper limb & $8 / 52(15 \%)$ \\
\hline Tone upper limb (\%) & & Lower limb & $8 / 45(18 \%)$ \\
\hline Normotonia & $38 / 42(90 \%)$ & Gait & $15 / 47(32 \%)$ \\
\hline Hypertonia & $4 / 42(10 \%)$ & Superficial sensory modalities & $6 / 66(9 \%)$ \\
\hline Tone lower limb (\%) & & Deep sensory modalities & $31 / 66(47 \%)$ \\
\hline Hypotonia & $1 / 54(2 \%)$ & Sphincter disturbances (\%) & $28 / 62(45 \%)$ \\
\hline Normotonia & $7 / 54(13 \%)$ & Bladder (mostly urinary urgency) & $26 / 62(42 \%)$ \\
\hline Hypertonia & $46 / 54(85 \%)$ & Anal & $9 / 62(15 \%)$ \\
\hline
\end{tabular}

Table 2: phenotypic characteristics in 72 SPAST mutation carriers, among which 5 were asymptomatic according to history. MRC: Medical Research Council scale. 


\begin{tabular}{|l|l|}
\hline & Number of patients $n=67$ \\
\hline Pure & $\mathbf{5 2}(\mathbf{7 7 . 6} \%)$ \\
\hline Complicated & $\mathbf{1 5}(\mathbf{2 2 . 4} \mathbf{\%})$ \\
- tremor & $7(10.4 \%)$ \\
- optic atrophy & $2(3.0 \%)$ \\
- polyneuropathy & $2(3.0 \%)$ \\
- thin corpus callosum & $2(3.0 \%)$ \\
- mental retardation & $1(1.5 \%)$ \\
- dementia & $1(1.5 \%)$ \\
- epilepsy & $1(1.5 \%)$ \\
- cerebellar atrophy & $1(1.5 \%)$ \\
\hline
\end{tabular}

Table 3: Pure versus complex phenotype of the 67 SPAST patients based on clinical and/or imaging features. 


\section{Reference list}

1. Strümpell A (1904) Die primäre Seitenstrangsklerose (spastische Spinalparalyse).Deutsche Zeitschrift für Nervenheilkunde 27:291-339-.

2. Hedera P, Eldevik OP, Maly P, Rainier S,Fink JK (2005) Spinal cord magnetic resonance imaging in autosomal dominant hereditary spastic paraplegia.Neuroradiology 47:730-734.

3. Krabbe K, Nielsen JE, Fallentin E, Fenger K,Herning M (1997) MRI of autosomal dominant pure spastic paraplegia.Neuroradiology 39:724-727.

4. Depienne C, Stevanin G, Brice A,Durr A (2007) Hereditary spastic paraplegias: an update.Curr.Opin.Neurol. 20:674-680.

5. Harding AE (1983) Classification of the hereditary ataxias and paraplegias.Lancet 1:1151-1155.

6. Salinas S, Proukakis C, Crosby A,Warner TT (2008) Hereditary spastic paraplegia: clinical features and pathogenetic mechanisms.Lancet Neurol. 7:1127-1138.

7. McMonagle P, Webb S,Hutchinson M (2002) The prevalence of "pure" autosomal dominant hereditary spastic paraparesis in the island of Ireland.J.Neurol.Neurosurg.Psychiatry 72:43-46.

8. Salinas S, Carazo-Salas RE, Proukakis C, Schiavo G,Warner TT (2007) Spastin and microtubules: Functions in health and disease.J.Neurosci.Res. 85:2778-2782.

9. Sauter S, Miterski B, Klimpe S, Bonsch D, Schols L, Visbeck A, Papke T, Hopf HC, Engel W, Deufel T, Epplen JT,Neesen J (2002) Mutation analysis of the spastin gene (SPG4) in patients in Germany with autosomal dominant hereditary spastic paraplegia.Hum.Mutat. 20:127-132.

10. Shoukier M, Neesen J, Sauter SM, Argyriou L, Doerwald N, Pantakani DV,Mannan AU (2009) Expansion of mutation spectrum, determination of mutation cluster regions and predictive structural classification of SPAST mutations in hereditary spastic paraplegia.Eur.J.Hum.Genet. 17:187-194.

11. Kumar P, Henikoff S,Ng PC (2009) Predicting the effects of coding non-synonymous variants on protein function using the SIFT algorithm.Nat.Protoc. 4:1073-1081.

12. Mathe E, Olivier M, Kato S, Ishioka C, Hainaut P,Tavtigian SV (2006) Computational approaches for predicting the biological effect of p53 missense mutations: a comparison of three sequence analysis based methods.Nucleic Acids Res. 34:1317-1325.

13. Depienne C, Fedirko E, Forlani S, Cazeneuve C, Ribai P, Feki I, Tallaksen C, Nguyen K, Stankoff B, Ruberg M, Stevanin G, Durr A,Brice A (2007) Exon deletions of SPG4 are a frequent cause of hereditary spastic paraplegia.J.Med.Genet. 44:281-284. 
14. Beetz C, Nygren AO, Schickel J, uer-Grumbach M, Burk K, Heide G, Kassubek J, Klimpe S, Klopstock T, Kreuz F, Otto S, Schule R, Schols L, Sperfeld AD, Witte OW,Deufel T (2006) High frequency of partial SPAST deletions in autosomal dominant hereditary spastic paraplegia.Neurology 67:1926-1930.

15. McDermott CJ, Burness CE, Kirby J, Cox LE, Rao DG, Hewamadduma C, Sharrack B, Hadjivassiliou M, Chinnery PF, Dalton A, Shaw PJ (2006) Clinical features of hereditary spastic paraplegia due to spastin mutation.Neurology 67:45-51.

16. Fonknechten N, Mavel D, Byrne P, Davoine CS, Cruaud C, Bonsch D, Samson D, Coutinho P, Hutchinson M, McMonagle P, Burgunder JM, Tartaglione A, Heinzlef O, Feki I, Deufel T, Parfrey N, Brice A, Fontaine B, Prud'homme JF, Weissenbach J, Durr A,Hazan J (2000) Spectrum of SPG4 mutations in autosomal dominant spastic paraplegia.Hum.Mol.Genet. 9:637-644.

17. McMonagle P, Byrne PC, Fitzgerald B, Webb S, Parfrey NA,Hutchinson M (2000) Phenotype of AD-HSP due to mutations in the SPAST gene: comparison with AD-HSP without mutations.Neurology 55:1794-1800.

18. Magariello A, Muglia M, Patitucci A, Mazzei R, Conforti FL, Gabriele AL, Sprovieri T, Ungaro C, Gambardella A, Mancuso M, Siciliano G, Branca D, Aguglia U, de Angelis MV, Longo K,Quattrone A (2006) Novel spastin (SPG4) mutations in Italian patients with hereditary spastic paraplegia.Neuromuscul.Disord. 16:387-390.

19. Depienne C, Tallaksen C, Lephay JY, Bricka B, Poea-Guyon S, Fontaine B, Labauge P, Brice A,Durr A (2006) Spastin mutations are frequent in sporadic spastic paraparesis and their spectrum is different from that observed in familial cases.J.Med.Genet. 43:259-265.

20. Molon A, Montagna P, Angelini C,Pegoraro E (2003) Novel spastin mutations and their expression analysis in two Italian families.Eur.J.Hum.Genet. 11:710-713.

21. Svenson IK, Kloos MT, Gaskell PC, Nance MA, Garbern JY, Hisanaga S, PericakVance MA, shley-Koch AE,Marchuk DA (2004) Intragenic modifiers of hereditary spastic paraplegia due to spastin gene mutations.Neurogenetics. 5:157-164.

22. Chinnery PF, Keers SM, Holden MJ, Ramesh V,Dalton A (2004) Infantile hereditary spastic paraparesis due to codominant mutations in the spastin gene.Neurology 63:710712.

23. Schickel J, Pamminger T, Ehrsam A, Munch S, Huang X, Klopstock T, Kurlemann G, Hemmerich P, Dubiel W, Deufel T,Beetz C (2007) Isoform-specific increase of spastin stability by N-terminal missense variants including intragenic modifiers of SPG4 hereditary spastic paraplegia.Eur.J.Neurol. 14:1322-1328.

24. Erichsen AK, Inderhaug E, Mattingsdal M, Eiklid K,Tallaksen CM (2007) Seven novel mutations and four exon deletions in a collection of Norwegian patients with SPG4 hereditary spastic paraplegia.Eur.J.Neurol. 14:809-814.

25. ROE PF (1963) HEREDITARY SPASTIC

PARAPLEGIA.J.Neurol.Neurosurg.Psychiatry 26:516-519. 
26. McMonagle P, Byrne P,Hutchinson M (2004) Further evidence of dementia in SPG4linked autosomal dominant hereditary spastic paraplegia.Neurology 62:407-410.

27. Fink JK and Rainier S (2004) Hereditary spastic paraplegia: spastin phenotype and function.Arch.Neurol. 61:830-833.

28. McDermott C, White K, Bushby K,Shaw P (2000) Hereditary spastic paraparesis: a review of new developments.J.Neurol.Neurosurg.Psychiatry 69:150-160.

29. Gutmann DH, Fischbeck KH,Kamholz J (1990) Complicated hereditary spastic paraparesis with cerebral white matter lesions.Am.J.Med.Genet. 36:251-257.

30. Kassubek J, Sperfeld AD, Baumgartner A, Huppertz HJ, Riecker A,Juengling FD (2006) Brain atrophy in pure and complicated hereditary spastic paraparesis: a quantitative 3D MRI study.Eur.J.Neurol. 13:880-886. 


\begin{tabular}{|c|c|c|c|c|c|}
\hline No & $\begin{array}{l}\text { Exon/ } \\
\text { intron }\end{array}$ & $\begin{array}{l}\text { cDNA } \\
\text { (nucleotide } \\
\text { change) }\end{array}$ & $\begin{array}{l}\text { Amino acid } \\
\text { change }\end{array}$ & Mutation type & Ref. \\
\hline 1 & Ex 1 & c. $131 \mathrm{C}>\mathrm{T}$ & p. Ser44Leu & $\begin{array}{l}\text { Missense } \\
\text { (polymorphism) }\end{array}$ & $\begin{array}{l}\text { Lindsey (2000) J Med } \\
\text { Genet } 37,759\end{array}$ \\
\hline 2 & Ex 1 & c. $134 \mathrm{C}>\mathrm{A}$ & p. Pro45Gln & Missense & $\begin{array}{l}\text { Svenson (2004) } \\
\text { Neurogenetics 5, } 157\end{array}$ \\
\hline 3 & Ex 1 & c. $153 \mathrm{C}>\mathrm{G}$ & p.Tyr51X & Nonsense & novel \\
\hline 4 & Ex 1 & c.155_156dup & p.Phe53fs & Duplication & novel \\
\hline 5 & Ex 1 & c.310del & p.Ala104fs & Deletion & novel \\
\hline 6 & Ex 1 & c.328_340del & p.Gly110fs & Deletion & novel \\
\hline 7 & Ex 1 & c. $412 \mathrm{~A}>\mathrm{T}$ & p.Lys $138 \mathrm{X}$ & Nonsense & $\begin{array}{l}\text { Vergouwen (2008) J } \\
\text { Neurol 255, } 303\end{array}$ \\
\hline 8 & Ex 2 & c. $484 \mathrm{G}>\mathrm{A}$ & p.Val162lle & Missense & novel \\
\hline 9 & $\ln 3$ & $\begin{array}{l}\text { c. } 586+9 \_586+1 \\
2 \mathrm{del}\end{array}$ & & Deletion & $\begin{array}{l}\text { Higgins (2001) } \\
\text { Neurology 56, } 1482\end{array}$ \\
\hline 10 & Ex 5 & c.790del & p.His264fs & Deletion & novel \\
\hline 11 & $\ln 5$ & c. $871-1 \mathrm{G}>\mathrm{A}$ & p.? & Splice mutation & $\begin{array}{l}\text { Shoukier (2009) Eur J } \\
\text { Hum Genet 17, } 187\end{array}$ \\
\hline 12 & $\ln 6$ & c. $1004+2 T>G$ & p.? & Splice mutation & $\begin{array}{l}\text { Fonknechten (2000) } \\
\text { Hum Mol Genet 9, } 637\end{array}$ \\
\hline 13 & $\ln 6$ & c. $1004+5 G>T$ & p.? & Splice mutation & $\begin{array}{l}\text { Loureiro (2009) Acta } \\
\text { Neurol Scand 119, } 113\end{array}$ \\
\hline 14 & $\ln 6$ & c. $1005-2 A>G$ & p.? & Splice mutation & $\begin{array}{l}\text { McDermott }(2006) \\
\text { Neurology } 67,45\end{array}$ \\
\hline 15 & Ex 7 & c. $1048 \mathrm{G}>\mathrm{C}$ & p.Ala350Pro & Missense & $\begin{array}{l}\text { Brugman (2005) Ann } \\
\text { Neurol 58, } 865\end{array}$ \\
\hline 16 & Ex 7 & c. $1061 \mathrm{~T}>\mathrm{A}$ & p.Leu354X & Nonsense & novel \\
\hline 17 & Ex 7 & c. $1066 \mathrm{G}>\mathrm{A}$ & p.Glu356Lys & Missense & novel \\
\hline 18 & Ex 7 & c.1069del & p.lle357fs & Deletion & novel \\
\hline 19 & Ex 7 & c. $1082 \mathrm{C}>\mathrm{T}$ & p.Pro361Leu & Missense & $\begin{array}{l}\text { Chinnery }(2004) \\
\text { Neurology } 63,710\end{array}$ \\
\hline 20 & Ex 7 & c. $1093 \mathrm{C}>\mathrm{T}$ & p.Pro365Ser & Missense & novel \\
\hline 21 & Ex 8 & c. $1144 \mathrm{G}>\mathrm{C}$ & p.Gly382Arg & Missense & novel \\
\hline 22 & $\ln 8$ & c. $1174-2 A>C$ & p.? & Splice site & novel \\
\hline 23 & Ex 9 & c.1174del & p.Ala392fs & Deletion & $\begin{array}{l}\text { Fonknechten }(2000) \\
\text { Hum Mol Genet 9, } 637\end{array}$ \\
\hline 24 & Ex 9 & c. $1196 C>T$ & p.Ser399Leu & Missense & $\begin{array}{l}\text { Meijer (2002) Arch } \\
\text { Neurol 59, } 281\end{array}$ \\
\hline 25 & Ex 9 & c. $1216 A>G$ & p.lle406Val & Missense & $\begin{array}{l}\text { Schickel }(2006) \\
\text { Neurology } 66,421\end{array}$ \\
\hline 26 & Ex 9 & c. $1220 G>T$ & p.Ser407Ile & Missense & novel \\
\hline 27 & Ex 9 & c. $1245 \mathrm{del}$ & p.Tyr415X & Deletion & $\begin{array}{l}\text { Shoukier (2009) Eur J } \\
\text { Hum Genet 17, } 187\end{array}$ \\
\hline 28 & $\ln 9$ & c. $1245+1 \mathrm{G}>\mathrm{C}$ & p.? & Splice site & novel \\
\hline
\end{tabular}




\begin{tabular}{|c|c|c|c|c|c|}
\hline 29 & $\ln 9$ & c. $1245+1 G>A$ & p.? & Splice site & $\begin{array}{l}\text { Svenson (2001) Am J } \\
\text { Hum Genet 68, } 1077\end{array}$ \\
\hline 30 & Ex 10 & c. $1266 \mathrm{G}>\mathrm{C}$ & p.Leu422Phe & Missense & novel \\
\hline 31 & Ex 10 & c. $1276 C>G$ & p. Leu426Val & Missense & $\begin{array}{l}\text { Fonknechten }(2000) \\
\text { Hum Mol Genet } 9,637\end{array}$ \\
\hline 32 & Ex 11 & c. $1324 G>T$ & p. Glu442X & Nonsense & $\begin{array}{l}\text { Brugman (2005) Ann } \\
\text { Neurol 58, } 865\end{array}$ \\
\hline 33 & Ex 11 & c. $1334 \mathrm{G}>\mathrm{A}$ & p.Ser445Asn & Missense & novel \\
\hline 34 & Ex 11 & c. $1378 \mathrm{C}>\mathrm{A}$ & p.Arg460Ser & Missense & novel \\
\hline 35 & Ex 11 & c. $1378 \mathrm{C}>\mathrm{T}$ & p.Arg460Cys & Missense & $\begin{array}{l}\text { Falco (2004) } \\
\text { Neuromuscul Disord } \\
\mathbf{1 4 , 7 5 0}\end{array}$ \\
\hline 36 & Ex 12 & c. $1444 G>C$ & p.Val482Leu & Missense & novel \\
\hline 37 & Ex 12 & c. $1466 C>T$ & p.Pro489Leu & Missense & $\begin{array}{l}\text { Meijer (2002) Arch } \\
\text { Neurol 59, 281 }\end{array}$ \\
\hline 38 & $\ln 12$ & $\begin{array}{l}\text { c. } 1493+2 \_1493 \\
+5 \text { del }\end{array}$ & p.? & Splice site & $\begin{array}{l}\text { Buerger (2000) Eur J } \\
\text { Hum Genetics }\end{array}$ \\
\hline 39 & Ex 13 & c. $1496 \mathrm{G}>\mathrm{A}$ & p.Arg499His & Missense & $\begin{array}{l}\text { Park (2005) Arch } \\
\text { Neurol 62, } 1118\end{array}$ \\
\hline 40 & Ex 13 & $\begin{array}{l}\text { c. } 1500 \_1501 \mathrm{ins} \\
T\end{array}$ & p.lle501fs & Insertion & novel \\
\hline 41 & Ex 13 & c.1534_1536del & p.Glu512del & Deletion & novel \\
\hline 42 & Ex 14 & c. $1600 \mathrm{C}>\mathrm{G}$ & p.Leu534Val & Missense & novel \\
\hline 43 & Ex 15 & c. $1625 A>G$ & p.Asp542Gly & Missense & $\begin{array}{l}\text { Brugman (2005) Ann } \\
\text { Neurol 58, } 865\end{array}$ \\
\hline 44 & Ex 15 & c.1628dup & p.Tyr544fs & Duplication & novel \\
\hline 45 & Ex 15 & c. $1685 \mathrm{G}>\mathrm{A}$ & p.Arg562Gln & Missense & $\begin{array}{l}\text { Meijer (2002) Arch } \\
\text { Neurol 59, 281 }\end{array}$ \\
\hline 46 & Ex 15 & c. $1685 \mathrm{G}>\mathrm{C}$ & p.Arg562Pro & Missense & novel \\
\hline 47 & $\ln 15$ & c. $1688-2 A>G$ & p.? & Splice mutation & $\begin{array}{l}\text { Hazan }(1999) \text { Nat } \\
\text { Genet 23, } 296\end{array}$ \\
\hline 48 & $\ln 16$ & c. $1729-2 \mathrm{~A}>\mathrm{T}$ & p.? & Splice mutation & $\begin{array}{l}\text { Ivanova (2006) Clin } \\
\text { Genet } 70,490\end{array}$ \\
\hline 49 & Ex 17 & c. $1735 \mathrm{~A}>\mathrm{C}$ & p.Asn579His & Missense & $\begin{array}{l}\text { Brugman (2005) Ann } \\
\text { Neurol 58, } 865\end{array}$ \\
\hline 50 & Ex 17 & c. $1741 \mathrm{C}>\mathrm{T}$ & p. $\operatorname{Arg} 581 X$ & Nonsense & $\begin{array}{l}\text { Patrono }(2005) \text { Hum } \\
\text { Mutat } 25,506\end{array}$ \\
\hline 51 & Ex 17 & c.1817del & p.Arg606fs & Deletion & novel \\
\hline 52 & Ex 17 & c. $1820 G>A$ & p.Trp607X & Nonsense & $\begin{array}{l}\text { Patrono }(2005) \text { Hum } \\
\text { Mutat 25, } 506\end{array}$ \\
\hline 53 & Ex 1 & c.1-?_415+?del & Unknown & Exon deletion & $\begin{array}{l}\text { Depienne (2007) J } \\
\text { Med Genet 44, } 281\end{array}$ \\
\hline 54 & Ex 2-17 & $\begin{array}{l}\text { c.416- } \\
? \_1851+? \mathrm{del}\end{array}$ & Unknown & Exon deletion & $\begin{array}{l}\text { Erichsen (2007) Eur J } \\
\text { Neurol 14, } 809\end{array}$ \\
\hline 55 & Ex 3-17 & $\begin{array}{l}\text { c.503- } \\
? \_1851+? \mathrm{del}\end{array}$ & Unknown & Exon deletion & novel \\
\hline 56 & Ex 4 & $\begin{array}{l}\text { c.587- } \\
? \_682+? \mathrm{del}\end{array}$ & Unknown & Exon deletion & novel \\
\hline 57 & Ex 8+9 & c.1099- & Unknown & Exon deletion & Svenstrup (2009) J \\
\hline
\end{tabular}




\begin{tabular}{|c|c|c|c|c|c|}
\hline 58 & Ex 9 & $\begin{array}{l}? \text { ? } 1245+? \mathrm{del} \\
\text { c.1174- } \\
? \_1245+? \mathrm{del}\end{array}$ & Unknown & Exon deletion & $\begin{array}{l}\text { Neurol Sci 284, } 90 \\
\text { Depienne (2007) J } \\
\text { Med Genet 44, } 281\end{array}$ \\
\hline 59 & $\begin{array}{l}\text { Ex } 14- \\
17\end{array}$ & $\begin{array}{l}\text { c. } 1537- \\
\text { ?_1851+?del }\end{array}$ & Unknown & Exon deletion & novel \\
\hline 60 & Ex 17 & $\begin{array}{l}\text { c. } 1729- \\
\text { ?_1851+?del }\end{array}$ & Unknown & Exon deletion & $\begin{array}{l}\text { Beetz }(2007) \text { Hum } \\
\text { Mutat } \mathbf{2 8 , 7 3 9}\end{array}$ \\
\hline
\end{tabular}

Supplementary table 1. All mutations found in the Dutch cohort of 151 SPAST mutation carriers, including the 27 novel mutations found. 
TM

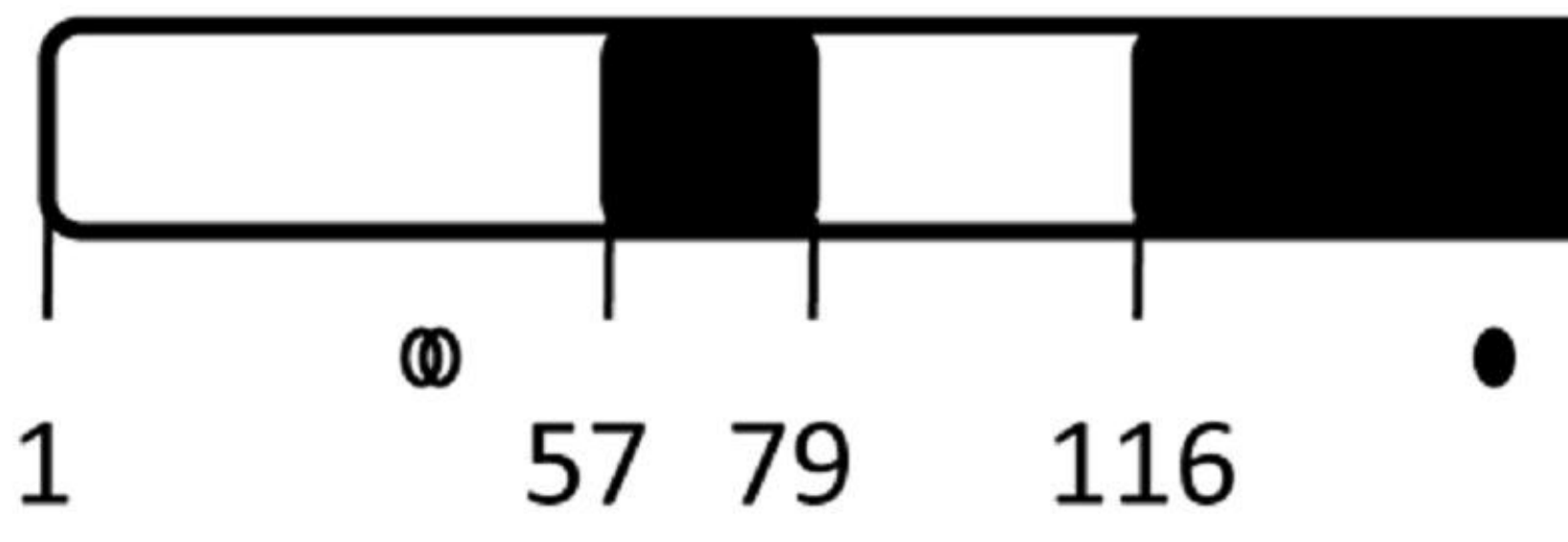

MIT

MTBD

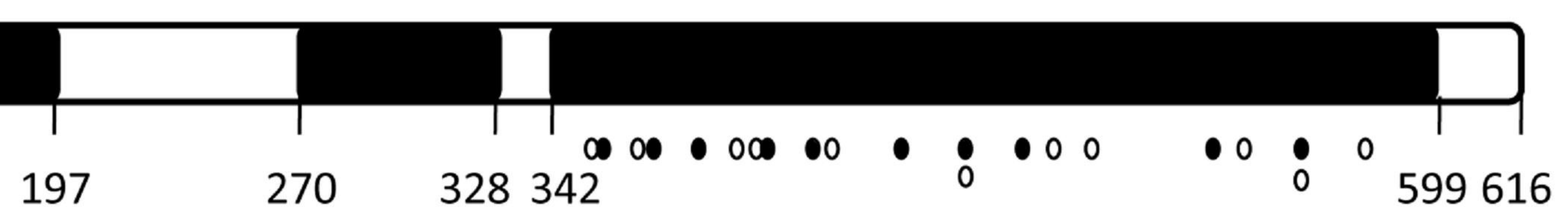




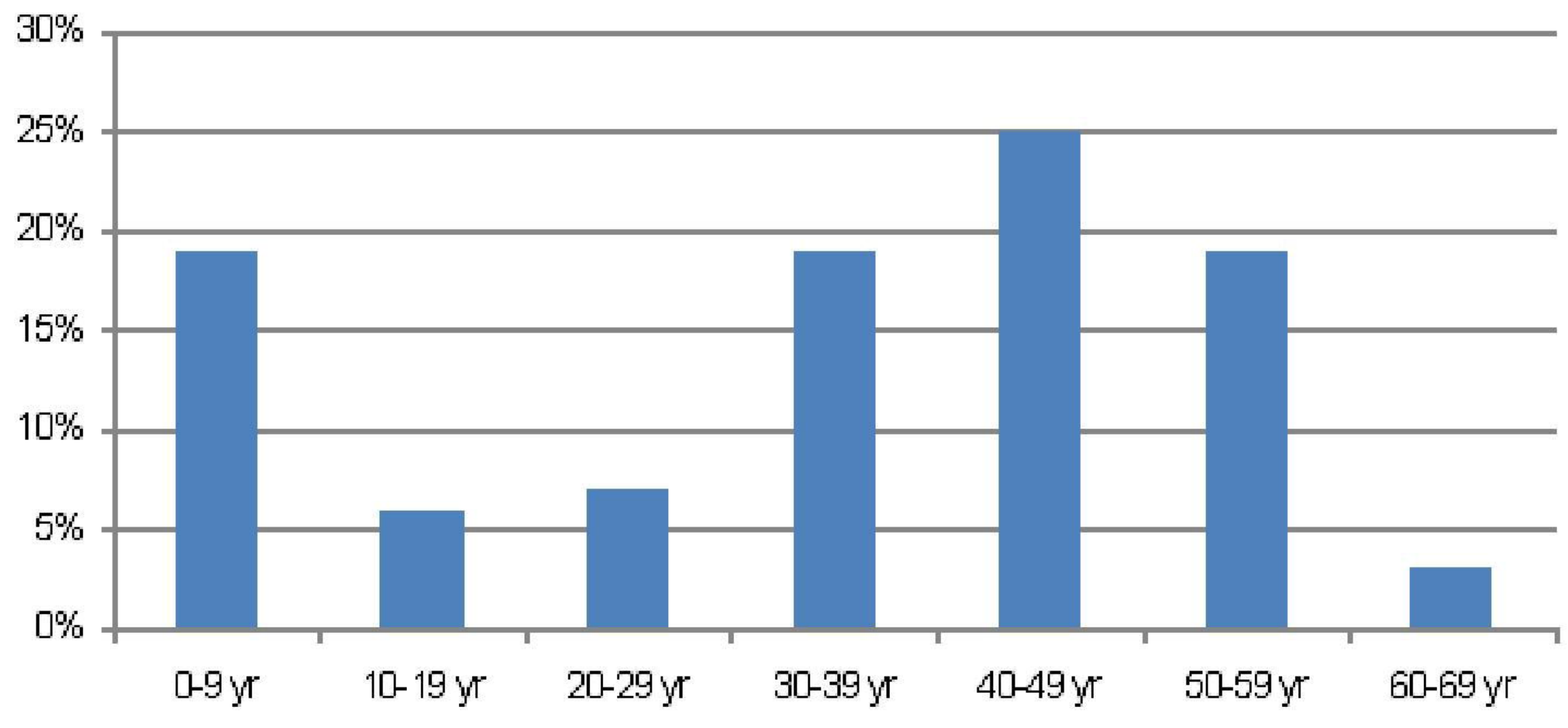

